\title{
Insulin protein and proliferation in ductal cells in the transplanted pancreas of patients with type 1 diabetes and recurrence of autoimmunity
}

\author{
A. Martin-Pagola • G. Sisino • G. Allende • \\ J. Dominguez-Bendala $\cdot$ R. Gianani $\cdot$ H. Reijonen . \\ G. T. Nepom • C. Ricordi • P. Ruiz • J. Sageshima • \\ G. Ciancio • G. W. Burke • A. Pugliese
}

Received: 25 March 2008 / Accepted: 27 June 2008 / Published online: 12 August 2008

(C) Springer-Verlag 2008

\begin{abstract}
Aim/hypothesis We investigated whether beta cell neoformation occurs in the transplanted pancreas in patients
\end{abstract}

Electronic supplementary material The online version of this article (doi:10.1007/s00125-008-1105-x) contains supplementary material, which is available to authorised users.

A. Martin-Pagola $\cdot$ G. Sisino $\cdot$ G. Allende $\cdot$

J. Dominguez-Bendala $\cdot$ C. Ricordi $\cdot$ G. W. Burke

A. Pugliese $(\square)$

Diabetes Research Institute, Leonard Miller School of Medicine,

University of Miami,

1450 NW 10th Avenue,

Miami, FL 33136, USA

e-mail: apuglies@med.miami.edu

J. Dominguez-Bendala C. Ricordi • P. Ruiz · J. Sageshima

G. Ciancio - G. W. Burke

Department of Surgery, Division of Transplantation,

Leonard Miller School of Medicine, University of Miami,

Miami, FL, USA

C. Ricordi $\cdot$ A. Pugliese

Department of Medicine, Leonard Miller School of Medicine,

University of Miami,

Miami, FL, USA

\section{A. Pugliese}

Department of Microbiology and Immunology,

Leonard Miller School of Medicine, University of Miami,

Miami, FL, USA

\section{R. Gianani}

Barbara Davis Center for Childhood Diabetes,

University of Colorado Health Sciences Center,

Aurora, CO, USA

H. Reijonen · G. T. Nepom

Benaroya Research Institute,

Seattle, WA, USA with type 1 diabetes who had received a simultaneous pancreas-kidney transplant (SPK) and later developed recurrence of autoimmunity.

Methods We examined pancreas transplant biopsies from nine SPK patients with or without recurrent autoimmunity or recurrent diabetes and from 16 non-diabetic organ donors. Tissues were analysed by immunohistochemistry and immunofluorescence.

Results Numerous cytokeratin-19 (CK-19) ${ }^{+}$pancreatic ductal cells stained for insulin in six SPK recipients with recurrent autoimmunity, in five of whom diabetes requiring insulin therapy recurred. These cells also stained for the transcription factor pancreatic-duodenal homeobox-1 (Pdx-1), which is implicated in pancreatic development and beta cell differentiation. The number of insulin ${ }^{+}$ ductal cells varied, being highest in the patient with the most severe beta cell loss and lowest in the normoglycaemic patient. In the patient with the most severe beta cell loss, we detected insulin ${ }^{+} \mathrm{CK}-19^{+} \mathrm{Pdx}-1^{+}$cells staining for the proliferation-related $\mathrm{Ki}-67$ antigen (Ki-67), indicating proliferation. We were unable to detect $\mathrm{Ki}-67^{+}$beta cells within the islets in any SPK patient. Some insulin ${ }^{+}$CK-19 ductal cells contained chromogranin A, suggesting further endocrine differentiation. Insulin ${ }^{+}$cells were rarely noted in the pancreas transplant ducts in three SPK patients without islet autoimmunity and in six of 16 non-diabetic organ donors; these insulin ${ }^{+}$cells were never CK-19 ${ }^{+}$.

Conclusions/interpretation Insulin ${ }^{+}$pancreatic ductal cells, some apparently proliferating, were found in the transplanted pancreas with recurrent islet autoimmunity/diabetes. Replicating beta cells were not detected within islets. The observed changes may represent attempts at tissue remodelling and beta cell regeneration involving ductal cells in the human transplanted pancreas, possibly stimulated by hyperglycaemia and chronic inflammation. 
Keywords Insulin · Pancreas transplantation · Pancreatic ducts $\cdot$ Pdx $-1 \cdot$ Recurrence of autoimmunity $\cdot$ Regeneration . Type 1 diabetes

$\begin{array}{ll}\text { Abbreviations } \\ \text { CgA } & \text { chromogranin A } \\ \text { CK-19 } & \text { cytokeratin-19 } \\ \text { Ki-67 } & \text { proliferation-related Ki-67 antigen } \\ \text { Pdx-1 } & \text { pancreatic duodenal homeobox-1 } \\ \text { SPK } & \text { simultaneous pancreas-kidney transplant }\end{array}$

\section{Introduction}

Type 1 diabetes is an autoimmune disease resulting in the destruction of pancreatic beta cells and insulin-dependence. However, residual insulin secretion is often detected at disease onset and marginal amounts of C-peptide are secreted by several patients even many years after diagnosis [1]. Consistently, beta cells are not completely absent in the pancreas of patients with type 1 diabetes [2-4]. A recent meta-analysis suggested that residual beta cell mass at diagnosis is related to age of onset, with younger patients having much more significant destruction than older ones [5]. Beta cells were found in $88 \%$ of autopsy pancreases from 42 patients with disease duration ranging between 4 and 67 years, appearing as single cells or small clusters. While this may simply reflect the survival of a few beta cells, the finding of ongoing beta cell apoptosis and the presence of non-apoptotic beta cells indirectly suggested beta cell neogenesis [6]. However, replication may be hampered by cytokine-induced damage and apoptosis associated with chronic autoimmunity, to which newly formed beta cells are sensitive [7, 8]. In mice, direct beta cell replication appears to be the main mechanism for maintaining beta cell mass [9] in physiological conditions such as pregnancy [10] and experimentally after pancreatectomy [11] or beta cell depletion induced by transgenically produced diphtheria toxin $[11,12]$. Other regenerative mechanisms include regeneration from pancreatic (and perhaps extra-pancreatic) precursor cells and transdifferentiation of other pancreatic (or extra-pancreatic) cell types [13-16]. Transdifferentiation and regeneration were reported in experimental conditions associated with tissue damage or beta cell loss, such as pancreatectomy [17], cellophane wrapping [18], ductal ligation [19, 20], streptozotocin treatment [21] and the development of autoimmune diabetes in nonobese diabetic mice $[21,22]$ and diabetesprone rats [23]. Pancreatic cells with features of ductal and beta cells in pancreatic ducts were originally characterised by electron microscopy [24]. Growing evidence suggests that ductal cells or precursors in the ducts may be involved in beta cell regeneration $[17,20,25-30]$; for example, human ductal cells transplanted into immunodeficient mice differentiate into new beta cells [30]. Rare insulin ${ }^{+}$cells in pancreatic ducts were reported in the pancreas of patients with long-standing type 1 diabetes [6], but the phenotype of those cells was not characterised further. Overall, there is growing evidence that pancreatic tissue damage may trigger several regenerative and remodelling mechanisms that may contribute to beta cell neogenesis [9].

Recurrence of autoimmunity and diabetes after pancreas transplantation was originally described in twins and HLAidentical siblings [31]. Other studies contributed evidence that recurrence of autoimmunity can occur regardless of HLA sharing and despite immunosuppression [32]. At our institution, we are following approximately 275 patients who received a simultaneous pancreas-kidney transplant (SPK) several years after developing type 1 diabetes. We are monitoring these patients for recurrence of autoimmunity, defined as the reactivation of humoral and/or cellular autoimmune responses, and have followed several patients to the full recurrence of type 1 diabetes requiring reinstitution of insulin therapy [33]. Most of these patients had no clinical signs of rejection associated with recurrent diabetes and maintained normal exocrine pancreas and kidney graft function. We were able to obtain pancreas transplant biopsies from several of these patients, which confirmed the diagnosis of recurrent diabetes and revealed variable degrees of insulitis and/or beta cell loss. In this study we investigated whether beta cell neoformation occurred in the transplanted pancreas of SPK patients with recurrent autoimmunity and diabetes, by examining the frequency, distribution, localisation and phenotype of insulin-producing cells.

\section{Methods}

Pancreases from transplant biopsies and deceased donors

We obtained open pancreas transplant biopsies from nine patients identified from a cohort of SPK recipients transplanted at the University of Miami. Patients included two women and seven men with a mean \pm SD age of $44.1 \pm$ 4.6 years (Table 1). All transplantation-related research procedures were approved by the University of Miami Institutional Review Board. Informed consent was obtained from all patients (or family members when appropriate) prior to transplantation and again prior to biopsy. We also examined 16 pancreases from non-diabetic, deceased organ donors, identified at the University of Miami and the University of Colorado, with written informed consent from the next of kin. These included seven women and nine men donors, with a mean \pm SD age of $40.8 \pm 14.5$ years (ESM Table 1). Additional features of the non-diabetic organ donors have been previously reported [34]. 
Diabetologia (2008) 51:1803-1813

1805

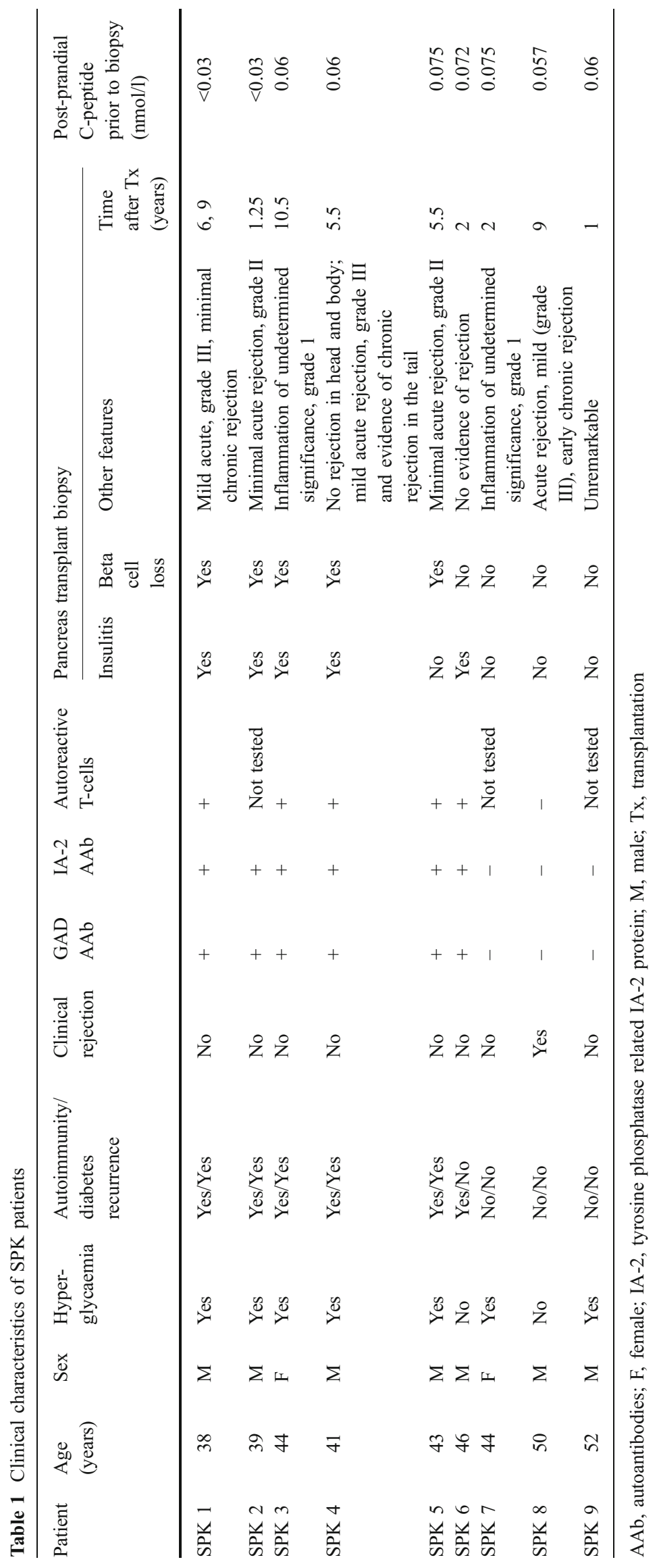

Ep Springer 
Clinical features of the SPK patients

As shown in Table 1, patients were assessed for recurrent autoimmunity, recurrent diabetes and rejection. We measured autoantibodies to GAD and the tyrosine phosphataselike protein IA-2 using standardised radioimmunoassays [35]. We tested for the presence of autoreactive CD4 and/or CD8 T cells using MHC class II/I tetramer assays, as described [36, 37]. Recurrent type 1 diabetes was diagnosed if the following criteria were met: (1) hyperglycaemia requiring insulin therapy; (2) clinical symptoms of diabetes in the presence of unchanged pancreas transplant exocrine function and kidney transplant function; (3) autoantibodies and/or autoreactive T cells in the circulation; (4) insulitis and/or beta cell loss at biopsy; (5) reduction in C-peptide levels.

Patients 1 to 6 had ongoing or recent recurrence of islet autoimmunity demonstrated by disease-associated autoantibodies and autoreactive T cells; five of six patients had both autoantibodies and autoreactive $\mathrm{T}$ cells. For patient 2, autoreactive $\mathrm{T}$ cells could not be determined. Patients 1 to 5 had become diabetic again by the time of biopsy and required insulin therapy. Biopsies showed variable degrees of beta cell loss and/or insulitis. Patient 1 had the most severe beta cell loss and had very little residual insulitis. Patients 2, 3 and 4 had both insulitis and significant beta cell loss. Patient 5 had no insulitis, but several islets showed reduced cellular content and reduced insulin staining. Patient 6 was normoglycaemic at the time of his accidental death, when the pancreas transplant was retrieved with the family's consent 2 years after transplantation. There was no evidence of beta cell destruction, and truly minimal insulitis. He had autoantibodies before and at the time of his death, when $\mathrm{T}$ cells were detected in peripheral blood, pancreas transplant lymph node and pancreas transplant tissue, reacting against GAD and proinsulin (unpublished data, H. Reijonen, G. Nepom, G.W. Burke and A. Pugliese). These data and other features of the biopsies are summarised in Table 1, but it should be noted that some inflammatory changes are almost invariably found in pancreas transplant biopsies even in the absence of clinical rejection. For comparison, we examined open pancreas transplant biopsies available from three SPK patients (patients 7-9) without evidence of recurrent autoimmunity. Patients 7 and 8 were normoglycaemic and had functioning grafts. Patient 8 could also be tested for GAD autoreactive T cells, which were not detected. This patient had evidence of mild acute and chronic rejection in the pancreas transplant biopsy but largely normal islets and insulin staining 9 years after transplantation. Patient 9 was hyperglycaemic and treated with insulin, although still secreting C-peptide, and is believed to have developed type 2 diabetes.
Immunohistochemistry and immunofluorescence

Pancreatic tissue from pancreas transplant biopsies and from non-diabetic organ donors was fixed in formalin and paraffin-embedded. Sections (5 $\mu \mathrm{m}$ thick) were cut and mounted on glass slides, which were stained using immunofluorescence and immunohistochemistry standard protocols, as described below.

Primary antibodies The following primary antibodies were used: mouse anti-insulin (1:100; clone K36AC10; Sigma, St Louis, MO, USA), guinea pig anti-insulin (pre-diluted; Biogenex, San Ramon, CA, USA), rabbit anti-glucagon (1:50; Dako, Carpinteria, CA, USA), goat anti-pancreatic duodenal homeobox-1 (Pdx-1; 1:5000; a gift from C. Wright, including an acid-eluted affinity-purified batch), mouse anti-cytokeratin-19 (CK-19; 1:50; Clone RCK108; Biogenex) and rabbit anti-CK-19 (1:100; ProteinTech, Chicago, IL, USA). We used a rabbit anti-proliferationrelated Ki-67 antigen (Ki-67) serum (1:50; Zymed Laboratories/Invitrogen, San Francisco, CA, USA) to assess proliferation [38] and both a rabbit serum (1:200; NeoMarkers, Fremont, CA, USA) and mouse monoclonal antibody (1:600; Clone LK2H10; NeoMarkers) to stain for chromogranin A ( $\mathrm{CgA})$, a protein found in secretory granules of endocrine cells [39].

Epitope retrieval For some stains, namely Pdx-1, Ki-67 and $\mathrm{CgA}$, epitope retrieval is necessary to successfully stain the tissues. Heat-induced epitope retrieval was performed as follows. For Pdx-1 staining, slides were boiled in Tris-EDTA (pH 9.0) in a hot plate for $30 \min \left(95-100^{\circ} \mathrm{C}\right)$. For Ki-67 staining, tissue sections were digested with trypsin for $10 \mathrm{~min}$ at $37^{\circ} \mathrm{C}$, followed by incubation for $5 \mathrm{~min}$ with citrate buffer $\left(\mathrm{pH}\right.$ 6.0) in a pressure cooker at $125^{\circ} \mathrm{C}$, using the protocol provided by the manufacturer (Zymed/Invitrogen). For $\mathrm{CgA}$ staining, tissue sections were incubated for $10 \mathrm{~min}$ with citrate buffer $\left(\mathrm{pH}\right.$ 6.0) in a pressure cooker at $120^{\circ} \mathrm{C}$. After all the various epitope retrieval treatments, sections were allowed to cool at room temperature for $30 \mathrm{~min}$.

Immunohistochemistry For insulin, glucagon, CK-19 and Ki-67 staining, we used the labelled-streptavidin-biotin method and a kit (Histostain Plus; Zymed/Invitrogen) according to the manufacturer's protocol. Formalin-fixed, paraffin-embedded tissue sections were deparaffinised and dehydrated in a graded series of ethanol washes. Tissue sections were subjected to epitope retrieval if required by the specific stain, as described above. After washing in PBS (pH 7.4), endogenous peroxidase was quenched using a 3\% solution (vol./vol.) of hydrogen peroxidase and methanol. Sections were washed with PBS and incubated with protein block (serum-free) reagent (Dako) to block non-specific 
staining. Slides were incubated with primary antibodies (1-3 h for insulin, glucagon and CK-19; overnight for Ki-67 at $4^{\circ} \mathrm{C}$ ). After washing in PBS, sections were incubated with biotinylated secondary antibody, washed again in PBS and incubated with horseradish peroxidase-conjugated streptavidin. The 3-amino, 9 ethyl-carbazole substrate revealed specific staining. Slides were counterstained with haematoxylin. For Pdx-1 staining, we used a kit (Vectastain ABC; Vector Laboratories, Burlingame, CA, USA), which also uses the peroxidase method but 3, 3'-diaminobenzidine as substrate. Slides were incubated overnight at $4{ }^{\circ} \mathrm{C}$ with the primary antibody (goat anti-Pdx-1). Negative control reactions included: (1) those in which the primary antibody was replaced by PBS or by the appropriate isotype-matched control antibody; (2) those in which the secondary antibody was omitted; and (3) those in which the streptavidin horseradish peroxidase conjugate was omitted to control for residual endogenous peroxidase activity. For Ki-67 staining, tonsil sections were used as positive control.

Immunofluorescence staining The following double and triple staining combinations were used to assess colocalisation: insulin/CK-19, Pdx-1/CK-19, insulin/Pdx-1, insulin/ Pdx-1/CK-19, insulin/CK-19/Ki-67 and insulin/CK-19/CgA. After deparaffinisation, tissue sections were subjected to epitope retrieval if required by the specific stain, as described above. Tissue sections were incubated with protein block (serum-free) reagent (Dako) to block non-specific staining. The first primary antibody was applied overnight at $4^{\circ} \mathrm{C}$ for $\mathrm{Ki}-67, \mathrm{Pdx}-1$ and insulin, and for $1-2 \mathrm{~h}$ at room temperature for CK-19 and CgA. After washing in PBS, the appropriate secondary antibodies were applied for $1 \mathrm{~h}$ at room temperature (1:400). Double and triple-immunofluorescence stains were carried out sequentially, so the above process was repeated for the second and third primary antibodies. The choice of secondary antibodies was such that the secondary antibodies could only react with their respective primary antibody. For all experiments, control reactions included: (1) the omission of the primary antibodies; (2) the replacement of the primary antibody with the appropriate isotype-matched irrelevant antibody; and (3) the omission of the secondary antibody. Secondary antibodies were fluorophore-labelled conjugates as follows: Alexa Fluor 568 goat anti-guinea pig IgG, Alexa-Fluor 488 chicken anti-goat IgG, Alexa-Fluor 647 goat anti-mouse IgG, Alexa-Fluor 488 goat anti-rabbit IgG and Alexa-Fluor 568 goat anti-mouse IgG (all from Invitrogen, Carlsbad, CA, USA).

\section{Microscopy}

Slides stained by immunohistochemistry were imaged using a Leica DMLB microscope connected to a Leica DFC-
420C digital camera (Leica Microsystems, Bannockburn, IL, USA) using the IM50 Image Manager software. For immunofluorescence, we used a Zeiss Axiovert 200M inverted microscope (Thornwood, NY, USA). Images were acquired digitally using a Hamamatsu ORCA-ER camera (Bridgewater, NJ, USA) and the Zeiss Axiovision 4.6.3 software. We used the following objectives: Plan-neofluar $10 \times / 0.3$ NA, Plan-neofluar $20 \times / 0.5$ NA, F-fluar $40 \times / 1.30$ oil and Plan-apochromat $63 \times / 1.40$ oil. Confocal microscopy was performed with a Zeiss LSM-510 microscope, equipped with the same objectives, to confirm colocalisation by Z-stack analysis.

\section{Results}

Insulin staining in pancreatic ductal cells

We examined pancreas transplant biopsies from nine SPK patients, of whom six (patients 1-6) had developed recurrent islet autoimmunity. Five of these patients (patients 1-5) had progressed to full diabetes recurrence with hyperglycaemia requiring reinstitution of insulin therapy by the time of biopsy. Table 1 shows the main clinical characteristics of the SPK patients and their stimulated Cpeptide levels at the time of biopsy. In the biopsies of patients 1 to 5 , insulin staining revealed the presence of numerous insulin ${ }^{+}$cells in the pancreatic ducts (Fig. 1a,b, $\mathrm{d}-\mathrm{m}$, Table 2). Two antibodies to insulin were used in separate experiments yielding similar results. The biopsy of patient 1, who had completely lost C-peptide secretion, showed the most severe beta cell loss and the most evident insulin staining in ductal cells (Fig. 1a,b,d-g). Indeed, most of the ducts examined $(127 / 141 ; 90 \%)$ and most ductal cells $(1,529 / 1,608 ; 95 \%)$ stained for insulin (Table 2). Patient 1 had two clinically justified pancreas transplant biopsies, approximately 3 years apart; the first biopsy was obtained 1 year after the patient had resumed insulin therapy. The presence of insulin ${ }^{+}$ductal cells was observed in both biopsy specimens. Insulin ${ }^{+}$ductal cells occurred in a variable number of ducts in patients 2 to 5 (Fig. $1 \mathrm{~h}-\mathrm{m}$, Table 2), ranging from $33 \%$ to $85 \%$ of the ducts examined. Specifically, in patients 2 to $5,65 \%, 33 \%, 82 \%$ and $85 \%$ respectively of the ducts examined had insulin ${ }^{+}$cells and $35 \%(400 / 1,134), 17 \%(294 / 1,429), 75 \%(541 / 714)$ and $65 \%(393 / 604)$ of the ductal cells stained for insulin. The intensity of the staining varied, but it was usually weaker than in beta cells in nearby islets, even if those beta cells were often in infiltrated islets as in patient 4 (Fig. $1 \mathrm{j}-1$ ) or in damaged islets as in patient 2 (Fig. 3b). There was no apparent pattern for duct type or size. In patient 2, many small ducts or duct-like structures resembling tubular complexes primarily stained for insulin (Fig. 1h). A similar 

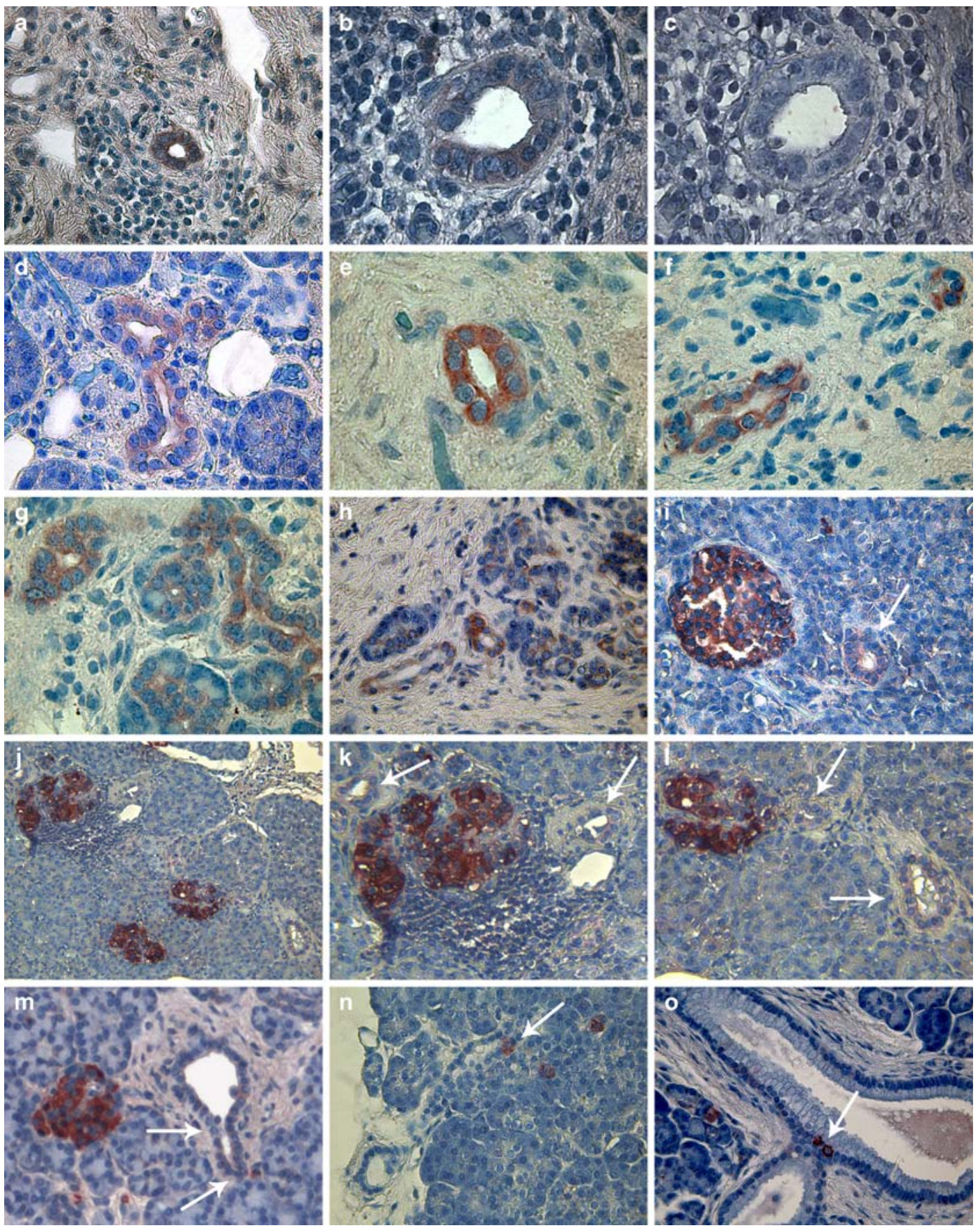

Fig. 1 Insulin $^{+}$cells in pancreatic ducts. Insulin protein was demonstrated by immunohistochemistry in pancreas transplant biopsies from 6 SPK patients with recurrent autoimmunity (a-n). Patients 1 to 5 (a-m), who had developed recurrence of diabetes, had the greatest number of ductal cells stained for insulin. a Patient 1, first biopsy; infiltrating lymphocytes are seen surrounding a duct containing insulin ${ }^{+}$cells. b, c Patient 1, second biopsy, serial sections stained for insulin and isotype control, respectively. Staining is weak (b), but distinct and clearly above background (c). d Patient 1, second biopsy, larger duct stained for insulin; staining is present also on the non-luminal side in many cells. e, f Patient 1 , second biopsy, ducts with intense insulin staining, and (g) patient 1, a few ducts and some smaller duct-like structures (lower right corner) stained for insulin. h Biopsy of patient 2, showing larger ducts and some smaller duct-like structures stained for insulin. i Biopsy of patient 3, insulin staining in a duct (arrow) is weaker than in the nearby islet. Some weaker staining is seen in the acinar tissue, possibly involving smaller duct-like structures. j Pancreas transplant biopsy of patient 4 , showing three islets, one of which was heavily infiltrated by lymphocytes. k, I Higher magnification $(\sim 2 \times)$ of details (j) to better visualise ducts containing insulin ${ }^{+}$cells (arrows). Some weaker and less distinct staining is seen in the acinar tissue, possibly involving smaller ductlike structures. m Pancreas transplant biopsy of patient 5; not all ductal cells stained for insulin (arrows); staining is also present on the non-luminal side in many cells. $\mathbf{n}$ Insulin $^{+}$cells (arrow) were rarely seen in a minority of ducts in patient 6; he had not yet developed significant insulitis and beta cell destruction, and was normoglycaemic. o Insulin ${ }^{+}$cells (arrow) were also rarely seen in control pancreases. Some single insulin ${ }^{+}$cells were also seen in the acinar tissue. Objective lens: $63 \times(\mathbf{a}, \mathbf{d}, \mathbf{f}, \mathbf{g}), 100 \times(\mathbf{b}, \mathbf{c}, \mathbf{e}), 40 \times(\mathbf{h}, \mathbf{i}$, $\mathbf{m}, \mathbf{n}, \mathbf{o}), 20 \times(\mathbf{j} ; \mathbf{k}, \mathbf{l}$ are details from $\mathbf{j}$ shown at higher magnification, $\sim 2 \times)$ 
Table 2 Enumeration of insulin-positive ductal cells

\begin{tabular}{lcc}
\hline Participants & $\begin{array}{c}\text { Insulin }^{+} \text {ductal cells per } \\
\text { ductal cells examined }\end{array}$ & $\begin{array}{c}\text { Ducts with insulin } \\
\text { per ducts examined }\end{array}$ \\
\hline Donor 1 & $8 / 173$ & $3 / 7$ \\
Donor 2 & $0 / 148$ & $0 / 6$ \\
Donor 3 & $0 / 160$ & $0 / 6$ \\
Donor 4 & $0 / 443$ & $0 / 16$ \\
Donor 5 & $0 / 98$ & $0 / 5$ \\
Donor 6 & $0 / 114$ & $0 / 5$ \\
Donor 7 & $0 / 392$ & $0 / 14$ \\
Donor 8 & $0 / 208$ & $0 / 8$ \\
Donor 9 & $1 / 162$ & $1 / 6$ \\
Donor 10 & $0 / 139$ & $0 / 6$ \\
Donor 11 & $0 / 152$ & $0 / 6$ \\
Donor 12 & $2 / 231$ & $1 / 8$ \\
Donor 13 & $6 / 188$ & $2 / 7$ \\
Donor 14 & $0 / 77$ & $0 / 4$ \\
Donor 15 & $8 / 1,579$ & $4 / 47$ \\
Donor 16 & $3 / 1,961$ & $3 / 85$ \\
SPK 1 & $1,529 / 1,608$ & $127 / 141$ \\
SPK 2 & $400 / 1,134$ & $37 / 57$ \\
SPK 3 & $294 / 1,429$ & $17 / 52$ \\
SPK 4 & $541 / 714$ & $61 / 74$ \\
SPK 5 & $393 / 604$ & $29 / 34$ \\
SPK 6 & $15 / 2,109$ & $7 / 99$ \\
SPK 7 & $1 / 798$ & $1 / 28$ \\
SPK 8 & $3 / 533$ & $2 / 18$ \\
SPK 9 & $1 / 413$ & $1 / 24$ \\
\hline & & \\
\hline
\end{tabular}

pattern was also observed in patient 1 (Fig. 1g) and patient 4 (Fig. 1j-1). Larger ducts were stained in other patients, for example patient 5 (Fig. $1 \mathrm{~m}$ ).

Patient 6 had evidence of recurrent autoimmunity, but had not developed diabetes. The examination of his pancreas transplant biopsy revealed no evidence of beta cell destruction. Only $7 \%$ of the ducts examined in his transplant biopsy contained insulin ${ }^{+}$cells and these were rare, representing less than $1 \%$ of the ductal cells $(15 / 2,109$; Fig. 1n, Table 2). Similarly, insulin ${ }^{+}$cells in the ducts were rarely noted in 6/16 control pancreases from non-diabetic organ donors who also tested negative for diabetesassociated autoantibodies (Fig. 1o, Table 2). For additional comparison we examined available pancreas transplant biopsies from 3 SPK patients (patients 7-9; Table 2), who had no evidence of recurrent autoimmunity. Patients 7 and 8 had functioning grafts and had normal glucose tolerance. Patient 9 had apparently developed type 2 diabetes. Insulin ${ }^{+}$ cells were rarely seen in the ducts of these patients, mainly consisting of single cells like the ones seen in the nondiabetic organ donors and amounting to less than $0.5 \%$ of the ductal cells examined in each patient (range 413-798 cells). The insulin ${ }^{+}$cells in the ducts did not co-stain for glucagon and we did not identify glucagon ${ }^{+}$cells in the ducts of our SPK patients. However, glucagon ${ }^{+}$cells were occasionally seen in the ducts of control pancreases (not shown).

Insulin $^{+}$cells in the pancreatic ducts of SPK patients with recurrent autoimmunity stain for CK-19 and Pdx-1

In order to better define the phenotype of the insulin ${ }^{+}$cells in the ducts and confirm that these were ductal cells, we stained serial sections by immunohistochemistry for insulin and CK19 (a marker of ductal cells), and for Pdx-1, a transcription factor that is required for pancreatic development and is found in mature beta cells and in ductal cells. We used double or triple immunofluorescence to assess colocalisation of insulin with CK-19 and Pdx-1. In the SPK patients with recurrent autoimmunity, including patient 6 , many but not all
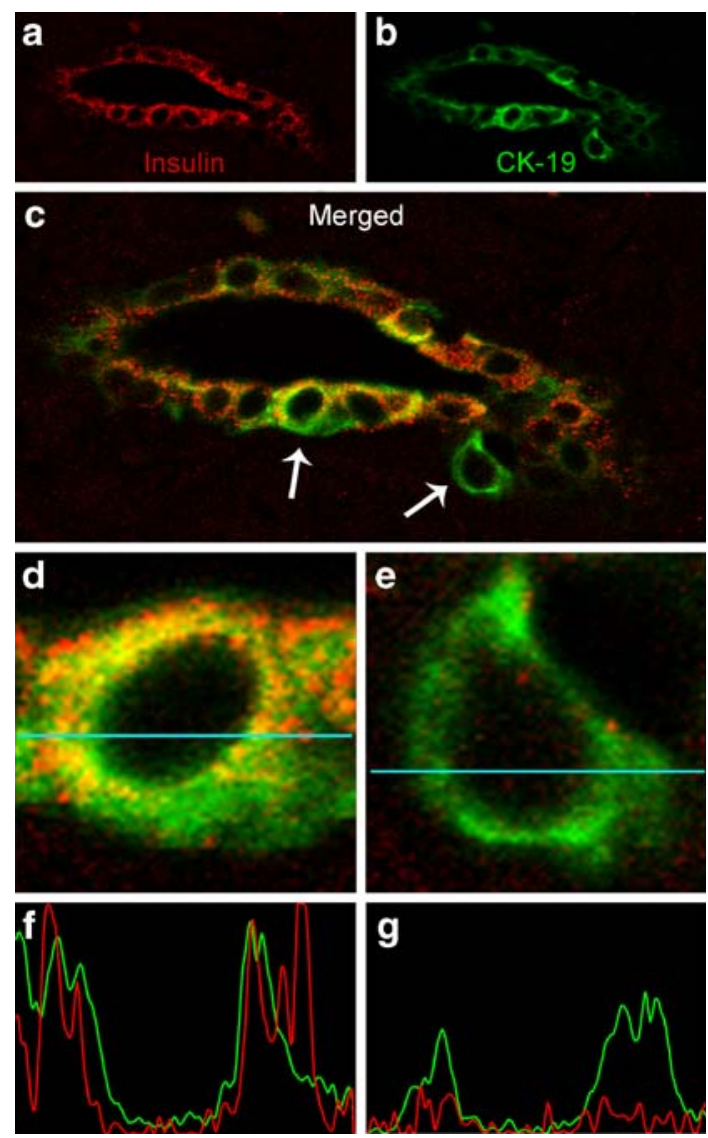

Fig. 2 Colocalisation of insulin and CK-19 in ductal cells of an SPK patient with recurrent autoimmunity. Sections are from the biopsy of patient 1 . Images were acquired using a confocal microscope with a $40 \times$ lens. a Staining for insulin, (b) CK-19 and (c) the former two merged. Note (c) the cell marked by the right arrow, which stained for CK-19 but did not stain for insulin. d, e Enlarged views of the single cells marked by arrows (c), which were (d) insulin ${ }^{+} \mathrm{CK}-19^{+}$and (e) $\mathrm{CK}-19^{+}$only. Colocalisation analysis was performed by confocal microscopy and is shown as graphs (f, $\mathbf{g})$, corresponding to the cells (d, e) respectively, for the data points collected along the horizontal line $(44 \mu \mathrm{m})$. Immunofluorescence is not detected when the line goes across the nucleus 

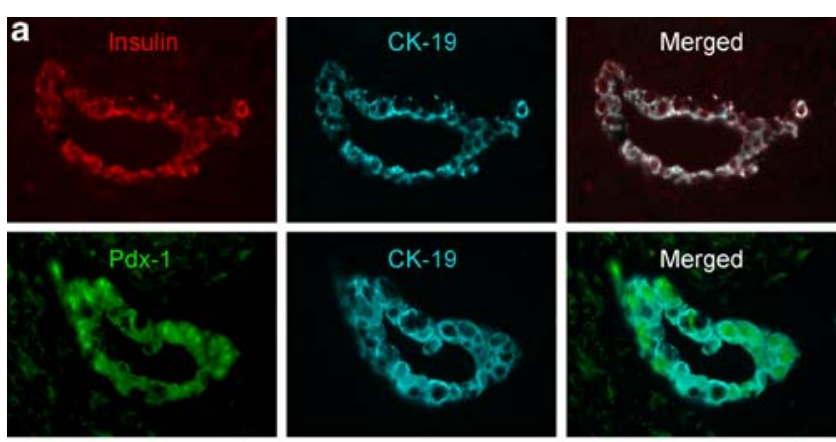

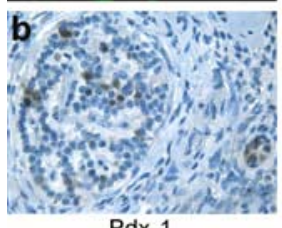

$\mathrm{Pdx}-1$

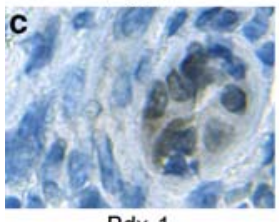

$\mathrm{Pdx}-1$
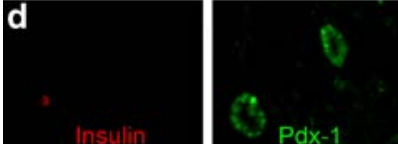

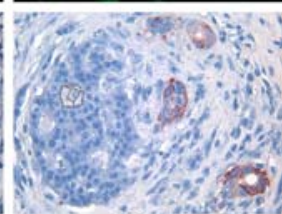
CK-19 Insulin

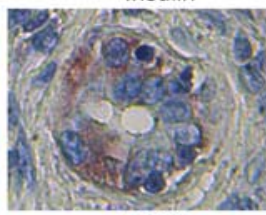
Insulin
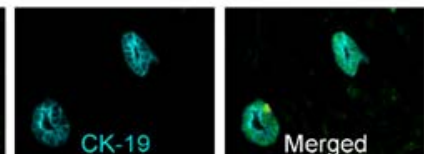

Fig. 3 Colocalisation of insulin, CK-19 and Pdx-1 in ductal cells of SPK patients with recurrent autoimmunity. a Insulin/CK-19 and CK$19 / \mathrm{Pdx}-1$ colocalisation, as indicated, in the ducts by double immunofluorescence using serial sections from the biopsy of patient 1. b Pdx-1, insulin and CK-19 staining in three serial sections of the transplanted pancreas of patient 2. A small duct is stained for insulin, CK-19 and Pdx-1 in the bottom right corners. A damaged islet with weak insulin staining is also seen. c Details highlighting the staining in the small duct (b). d Insulin/CK-19/Pdx-1 colocalisation by triple immunofluorescence for patient 6 . Objective lens: $40 \times(\mathbf{a}-\mathbf{d})$

of the insulin ${ }^{+}$cells in the ducts co-stained for CK-19 as seen in patient 1 (Fig. 2) (for original image of the corresponding confocal plane from the Z-stack series, see Electronic supplementary material [ESM] Fig. 1). This, in addition to the anatomical localisation, confirmed that these were indeed ductal cells. The insulin ${ }^{+} \mathrm{CK}-19^{+}$cells also stained for Pdx-1, demonstrating features of both endocrine and ductal cells (Fig. 3). Usually, insulin ${ }^{+} \mathrm{CK}-19^{+}$ductal cells stained more strongly for Pdx-1 than $\mathrm{CK}-19^{+}$insulin $^{-}$cells, which also sometimes showed no Pdx-1 staining (Fig. 3d). As noted, we observed rare insulin ${ }^{+}$cells in the ducts of three additional SPK patients (patients 7-9) without autoimmunity and in $6 / 16$ pancreases from non-diabetic organ donors. In contrast to the SPK patients with recurrent autoimmunity, the insulin ${ }^{+}$ cells identified in the ducts of those without autoimmunity (not shown) and in the control pancreases (Fig. 4a, ESM Fig. 2) did not stain for CK-19. Consistent with an endocrine phenotype, those cells stained for Pdx-1 (not shown).
Ki-67 staining in insulin ${ }^{+}$ductal cells

By staining for the proliferation marker Ki-67, we investigated whether proliferation could be observed in insulin $^{+}$cells, in islets or ducts. In patient 1 , in whom beta cell destruction was the most severe, we observed insulin ${ }^{+}$ CK $-19^{+} \mathrm{Pdx}-1^{+}$cells which, albeit rarely, showed nuclear Ki-67 staining, indicating proliferation (Fig. 4b, ESM Fig. 3). Ki-67 staining was not observed in the insulin ${ }^{+}$ ductal cells of the other five SPK patients with recurrent autoimmunity (not shown) or in those of the non-diabetic pancreas organ donors (Fig. 4a, ESM Fig. 2). We did not observe Ki- $67^{+}$beta cells in the islets of any of the pancreas transplant biopsies from the SPK patients with recurrent autoimmunity.

\section{CgA staining in insulin ${ }^{+}$ductal cells}

While most of the insulin ${ }^{+} \mathrm{CK}-19^{+}$ductal cells did not stain for $\mathrm{CgA}$, we observed ductal structures containing insulin ${ }^{+}$ $\mathrm{CgA}^{+}$cells. Importantly, these cells did not stain for CK-19.
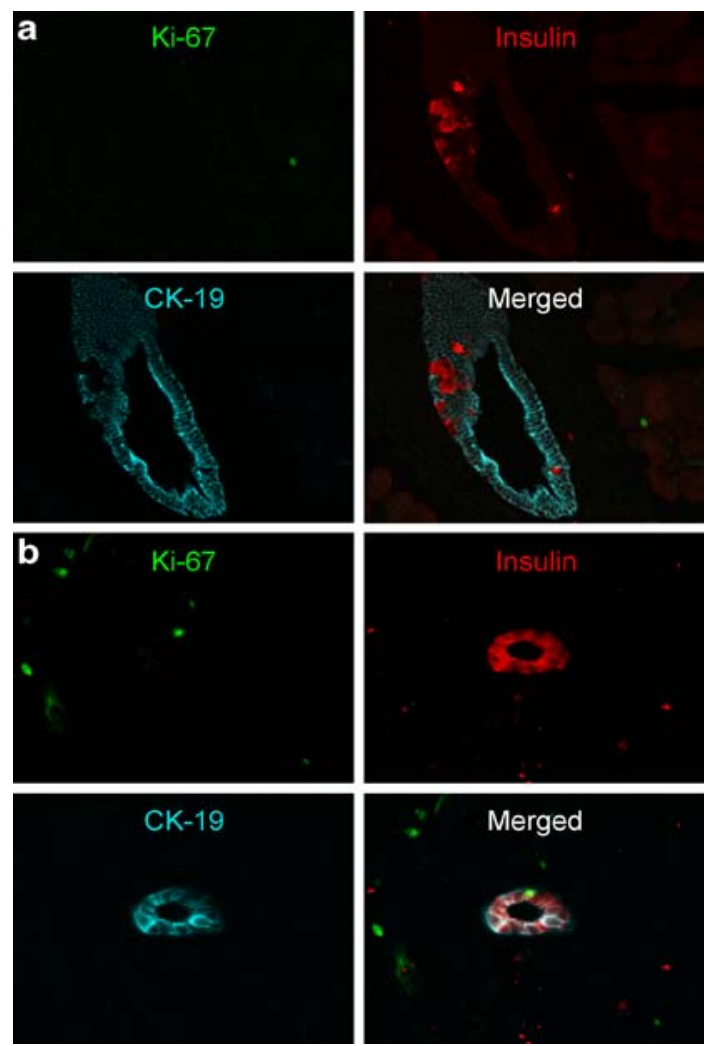

Fig. 4 Colocalisation analysis of insulin, CK-19 and Ki-67. a Absence of colocalisation of insulin and CK-19 in control pancreas 15. A Ki- $67^{+}$cell is shown outside the duct. b Colocalisation of insulin, CK-19 and Ki-67 in the pancreas transplant biopsy of patient 1. Colocalisation of insulin with CK-19 was seen, and one cell in the duct also stained for Ki-67. Objective lens: $20 \times($ a) and $40 \times($ b) 

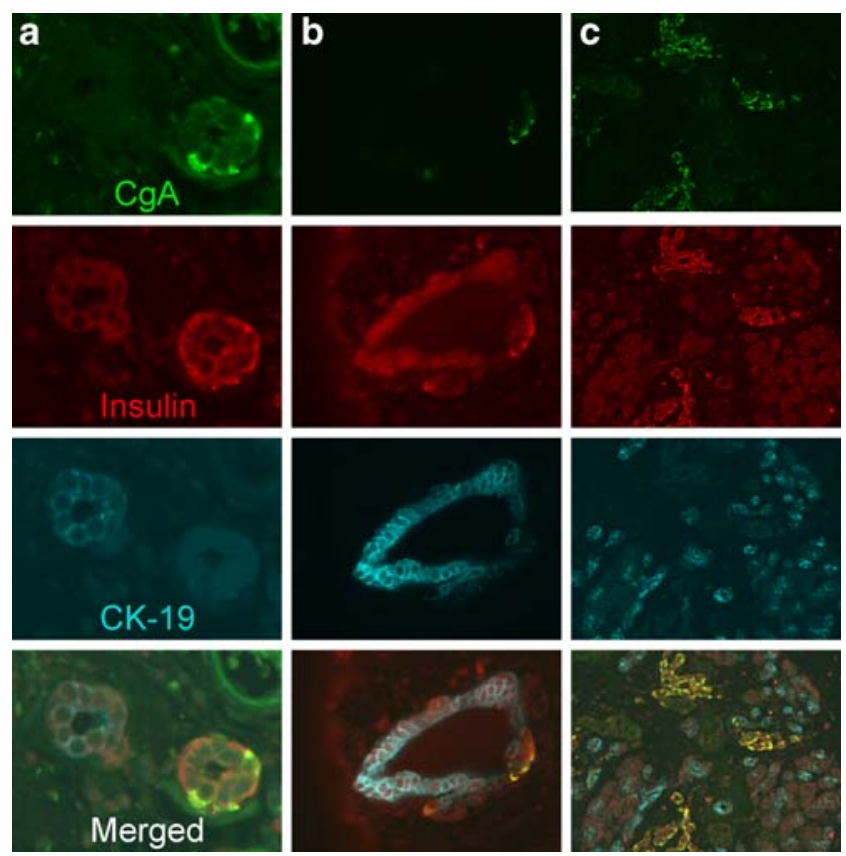

Fig. 5 Insulin $^{+} \mathrm{CgA}^{+}$ductal cells do not stain for CK-19. The figure illustrates the exclusive presence of CK-19 and CgA in insulin ${ }^{+}$ductal cells in patient 1 (a), patient 5 (b) and patient 2 (c). Some background staining is visible in the nuclei but clear cytoplasmic staining is seen in the cells co-staining for CgA. Weaker cytoplasmic staining, but above nuclear background, also seems visible in a few other cells that did not stain for CgA. Objective lens: $20 \times$ (a) with $4 \times$ zoom, $40 \times($ b) and $20 \times($ c)

Figure 5a shows two ducts from the second biopsy of patient 1 . In one of these ducts, cells stained for insulin together with CK-19; in another duct, cells stained for insulin and $\mathrm{CgA}$ but not for CK-19. Insulin staining was more intense in the latter duct. Figure $5 \mathrm{~b}$ shows coexistence of insulin ${ }^{+} \mathrm{CK}-19^{+} \mathrm{CgA}^{-}$cells with insulin ${ }^{+} \mathrm{CK}-19^{-} \mathrm{CgA}^{+}$ cells in the same duct (biopsy of patient 5). Figure $5 \mathrm{c}$ shows ductal structures, observed in the biopsy of patient 2, staining for insulin and $\mathrm{CgA}$ in the absence of CK-19, which is, however, detected in other small ductal structures nearby.

\section{Discussion}

Our study of pancreas transplant biopsies provides evidence connecting the ductal and beta cell phenotypes in the human pancreas, further supporting the concept that ductal cells may give origin to new beta cells under certain conditions. We demonstrate the existence of insulin ${ }^{+}$ductal cells, confirmed by CK-19 colocalisation, in the ducts of the transplanted pancreas, specifically in SPK patients with recurrent autoimmunity and diabetes. These cells stained for Pdx-1, a transcription factor that is required for pancreatic development and is found in mature beta cells $[40,41]$ and in ductal cells that do not contain insulin [42].
The number of insulin ${ }^{+}$ductal cells varied between 33 and $90 \%$ of the ductal cells examined. Similarly, $17 \%$ to $95 \%$ of the ducts had insulin ${ }^{+}$cells, indicating that these phenomena were quite extensive. The patient with the most severe beta cell destruction and complete loss of C-peptide secretion at the time of biopsy was the one with the highest number of ducts containing insulin ${ }^{+}$cells (patient 1). A consistent feature observed in our SPK patients with recurrence of autoimmune diabetes was that most, although not all (Fig. 2c, e), ductal cells were insulin ${ }^{+}$in those ducts that contained insulin ${ }^{+}$cells. In contrast, SPK patient 6 , who was normoglycaemic and without beta cell loss, although with clear evidence of ongoing autoimmunity, rarely had cells in the ducts that stained for insulin, CK-19 and Pdx-1. Thus, the presence of hyperglycaemia and autoimmunity may be critical for triggering insulin synthesis in ductal cells.

By comparison, we rarely observed insulin ${ }^{+}$cells in the ducts of non-diabetic organ donors. Importantly, while those cells were $\mathrm{Pdx}-1^{+}$, they did not contain CK-19. Similarly, we rarely observed insulin ${ }^{+}$cells in the ducts when we examined pancreas transplant biopsies from SPK patients without apparent islet autoimmunity, of whom two were normoglycaemic and one had developed type 2 diabetes. Mirroring the observations in non-diabetic pancreas donors, these cells did not stain for CK-19. The findings in these SPK patients without autoimmunity and in the non-diabetic organ donors are consistent with earlier reports of single insulin ${ }^{+}$cells in close association with ductal structures in the normal human pancreas [43].

Insulin and Pdx-1 synthesis in CK- $19^{+}$ductal cells, with a pattern similar to that in our SPK patients with recurrent autoimmunity and diabetes, was noted in human pancreases from patients with autoimmune chronic pancreatitis with diabetes [44]. This condition is similar to recurrence of autoimmune diabetes in the transplanted pancreas in that both autoimmunity and hyperglycaemia are present. Thus, there are now two studies of human pancreases suggesting that hyperglycaemia and chronic autoimmunity/inflammation may stimulate pancreas remodelling pathways including insulin production in ductal cells. A similar role for autoimmunity and inflammation in driving beta cell selfreplication has been suggested by mouse studies [22] Moreover, autoimmunity and diabetes have been associated with beta cell and islet neoformation in diabetes-prone rats [23], with regeneration occurring in tubular complexes, which resemble the small ductal structures that stained for insulin in the biopsies of patient 1 (Fig. $1 \mathrm{~g}$ ) and patient 2 (Fig. 1h).

Another study of patients with pancreatitis of unspecified aetiology reported the presence of cells staining for insulin or glucagon or Pdx-1 in pancreatic ducts [45]. However, this study did not show colocalisation of islet 
hormones with $\mathrm{CK}-19$ or Ki-67, although Ki-67-positive cells were noted in the ducts. Here, in contrast, we found that insulin ${ }^{+} \mathrm{CK}-19^{+}$cells can also stain for Ki-67, suggesting that these cells are capable of replication. This was noted in the patient with the most severe beta cell destruction, again suggesting a possible link between the replication of insulin $^{+}$ductal cells and the severity of beta cell loss/ hyperglycaemia. We did not observe $\mathrm{Ki}-67^{+}$cells among the surviving beta cells in the islets of any of the SPK patients with recurrent autoimmunity. However, we must recognise the limitations associated with the study of biopsy materials, in particular when assessing direct beta cell replication. Moreover, our SPK patients were immunosuppressed with tacrolimus, which inhibits direct beta cell replication in mice [12]. On the other hand, the formation of beta cells from ductal cells may be enhanced by chronic immunosuppression if this antagonises chronic autoimmunity.

Three of our SPK patients with recurrent autoimmunity (patients 1,2 and 5) also had ductal cells staining for both insulin and $\mathrm{CgA}$, a protein found in the secretory granules of endocrine cells, including pancreatic beta cells [39]. Importantly, those insulin ${ }^{+} \mathrm{CgA}^{+}$cells no longer stained for CK-19, while clearly being present in ductal structures. Various stages of this putative transition were observed in these patients, with some ducts having mixed cell composition (insulin ${ }^{+} \mathrm{CgA}^{+} \mathrm{CK}-19^{-}$and insulin ${ }^{+} \mathrm{CK}-19^{+} \mathrm{CgA}^{-}$, the latter representing the majority). This observation provides further evidence for the differentiation potential of ductal cells towards an endocrine phenotype, accompanied by an apparent loss of ductal cell features. Among these three patients, patients 1 and 2 had undetectable C-peptide levels, even after stimulation, in the days preceding the biopsy. The absence of C-peptide secretion in these patients seems consistent with the rareness of insulin ${ }^{+} \mathrm{CgA}^{+}$ductal cells, despite a high overall proportion of insulin ${ }^{+}$ductal cells. Based on the C-peptide data and on the rareness of this putative transition towards a more mature beta cell phenotype, we speculate that if these cells secrete insulin, this may be of negligible clinical significance.

In conclusion, our findings suggest that ductal cells participate in beta cell regenerative processes occurring in the transplanted human pancreas, in the context of hyperglycaemia and recurrent autoimmunity, and that these may be critical stimuli to trigger pancreas remodelling mechanisms in the adult. Dissecting the mechanisms involved in these remodelling processes could lead to therapeutic exploitation.

Acknowledgements This study was supported by the Diabetes Research Institute Foundation and in part by a grant from NIDDK (R01 DK070011-01A1). We acknowledge the support of the University of Miami Analytical Imaging Core, partly funded by the Juvenile Diabetes Research Foundation (Center Grant JDRFI 4-2004-361). G. McNamara, B. Frydel and B. Shaw assisted with confocal microscopy. K. Johnson assisted with tissue processing and histology. We thank C. Wright and M. Ray, Department of Cell and Developmental Biology, Vanderbilt University Medical Center (Nashville, TN, USA) and H. Edlund, Umea Center for Molecular Medicine, University of Umea (Umea, Sweden) for providing Pdx-1 anti-sera and for helpful discussion of the results.

Duality of interest The authors declare that there is no duality of interest associated with this manuscript.

\section{References}

1. Tsai EB, Sherry NA, Palmer JP, Herold KC (2006) The rise and fall of insulin secretion in type 1 diabetes mellitus. Diabetologia 49:261-270

2. Gepts W, De Mey J (1978) Islet cell survival determined by morphology. An immunocytochemical study of the islets of Langerhans in juvenile diabetes mellitus. Diabetes 27:251-261

3. Rahier J, Goebbels RM, Henquin JC (1983) Cellular composition of the human diabetic pancreas. Diabetologia 24:366-371

4. Lohr M, Kloppel G (1987) Residual insulin positivity and pancreatic atrophy in relation to duration of chronic type 1 (insulin-dependent) diabetes mellitus and microangiopathy. Diabetologia 30:757-762

5. Klinke DJ (2008) Extent of beta cell destruction is important but insufficient to predict the onset of type 1 diabetes mellitus. PLoS ONE 3:e1374

6. Meier JJ, Bhushan A, Butler AE, Rizza RA, Butler PC (2005) Sustained beta cell apoptosis in patients with long-standing type 1 diabetes: indirect evidence for islet regeneration? Diabetologia 48:2221-2228

7. Butler AE, Galasso R, Meier JJ, Basu R, Rizza RA, Butler PC (2007) Modestly increased beta cell apoptosis but no increased beta cell replication in recent-onset type 1 diabetic patients who died of diabetic ketoacidosis. Diabetologia 50:2323-2331

8. Meier JJ, Ritzel RA, Maedler K, Gurlo T, Butler PC (2005) Increased vulnerability of newly forming beta cells to cytokineinduced cell death. Diabetologia 49:83-89

9. Bouwens L (2006) Beta cell regeneration. Curr Diabetes Rev 2:3-9

10. Sorenson RL, Brelje TC (1997) Adaptation of islets of Langerhans to pregnancy: beta-cell growth, enhanced insulin secretion and the role of lactogenic hormones. Horm Metab Res 29:301-307

11. Dor Y, Brown J, Martinez OI, Melton DA (2004) Adult pancreatic beta-cells are formed by self-duplication rather than stem-cell differentiation. Nature 429:41-46

12. Nir T, Melton DA, Dor Y (2007) Recovery from diabetes in mice by beta cell regeneration. J Clin Invest 117:2553-2561

13. Habener JF, Kemp DM, Thomas MK (2005) Minireview: transcriptional regulation in pancreatic development. Endocrinology 146:1025-1034

14. Lardon J, Bouwens L (2005) Metaplasia in the pancreas. Differentiation 73:278-286

15. Li WC, Yu WY, Quinlan JM, Burke ZD, Tosh D (2005) The molecular basis of transdifferentiation. J Cell Mol Med 9:569-582

16. Bonner-Weir S, Sharma A (2006) Are there pancreatic progenitor cells from which new islets form after birth? Nat Clin Pract Endocrinol Metab 2:240-241

17. Sharma A, Zangen DH, Reitz P et al (1999) The homeodomain protein IDX-1 increases after an early burst of proliferation during pancreatic regeneration. Diabetes 48:507-513

18. Rafaeloff R, Pittenger GL, Barlow SW et al (1997) Cloning and sequencing of the pancreatic islet neogenesis associated protein (INGAP) gene and its expression in islet neogenesis in hamsters. $\mathrm{J}$ Clin Invest 99:2100-2109 
19. Wang RN, Kloppel G, Bouwens L (1995) Duct- to islet-cell differentiation and islet growth in the pancreas of duct-ligated adult rats. Diabetologia 38:1405-1411

20. Xu X, D'Hoker J, Stange G et al (2008) Beta cells can be generated from endogenous progenitors in injured adult mouse pancreas. Cell 132:197-207

21. Fernandes A, King LC, Guz Y, Stein R, Wright CV, Teitelman G (1997) Differentiation of new insulin-producing cells is induced by injury in adult pancreatic islets. Endocrinology 138:1750-1762

22. Sherry NA, Kushner JA, Glandt M, Kitamura T, Brillantes AM, Herold KC (2006) Effects of autoimmunity and immune therapy on beta-cell turnover in type 1 diabetes. Diabetes 55:3238-3245

23. Wang GS, Rosenberg L, Scott FW (2005) Tubular complexes as a source for islet neogenesis in the pancreas of diabetes-prone BB rats. Lab Invest 85:675-688

24. Melmed RN, Benitez CJ, Holt SJ (1972) Intermediate cells of the pancreas. I. Ultrastructural characterization. J Cell Sci 11:449-475

25. Bogdani M, Lefebvre V, Buelens N et al (2003) Formation of insulin-positive cells in implants of human pancreatic duct cell preparations from young donors. Diabetologia 46:830-838

26. Bonner-Weir S, Toschi E, Inada A et al (2004) The pancreatic ductal epithelium serves as a potential pool of progenitor cells. Pediatr Diabetes 5:16-22

27. Rescan C, Le BS, Lefebvre VH et al (2005) EGF-induced proliferation of adult human pancreatic duct cells is mediated by the MEK/ERK cascade. Lab Invest 85:65-74

28. Suarez-Pinzon WL, Yan Y, Power R, Brand SJ, Rabinovitch A (2005) Combination therapy with epidermal growth factor and gastrin increases beta-cell mass and reverses hyperglycemia in diabetic NOD mice. Diabetes 54:2596-2601

29. Suarez-Pinzon WL, Lakey JR, Brand SJ, Rabinovitch A (2005) Combination therapy with epidermal growth factor and gastrin induces neogenesis of human islet beta-cells from pancreatic duct cells and an increase in functional beta-cell mass. J Clin Endocrinol Metab 90:3401-3409

30. Yatoh S, Dodge R, Akashi T et al (2007) Differentiation of affinity-purified human pancreatic duct cells to beta-cells. Diabetes 56:1802-1809

31. Sutherland DE, Sibley R, Xu XZ et al (1984) Twin-to-twin pancreas transplantation: reversal and reenactment of the pathogenesis of type I diabetes. Trans Assoc Am Physicians 97:80-87

32. Tyden G, Reinholt FP, Sundkvist G, Bolinder J (1996) Recurrence of autoimmune diabetes mellitus in recipients of cadaveric pancreatic grafts. N Engl J Med 335:860-863

33. Diamantopoulos S, Allende G, Martin-Pagola A et al (2007) Recurrence of type 1 diabetes (T1DR) after simultaneous pancreas- kidney (SPK) transplantation is associated with islet cell autoantibody conversion. Acta Diabetologica 44(S1):s13 (Abstract)

34. Gianani R, Putnam A, Still T et al (2006) Initial results of screening of nondiabetic organ donors for expression of islet autoantibodies. J Clin Endocrinol Metab 91:1855-1861

35. Bingley PJ, Bonifacio E, Mueller PW (2003) Diabetes antibody standardization program: first assay proficiency evaluation. Diabetes 52:1128-1136

36. Reijonen H, Novak EJ, Kochik S et al (2002) Detection of GAD65-specific T cells by major histocompatibility complex class II tetramers in type 1 diabetic patients and at-risk subjects. Diabetes 51:1375-1382

37. Laughlin E, Burke G, Pugliese A, Falk B, Nepom GT (2008) Recurrence of autoreactive antigen-specific CD4+ $\mathrm{T}$ cells in autoimmune diabetes after pancreas transplantation. Clin Immunol 128:23-30

38. Scholzen T, Gerdes J (2000) The Ki-67 protein: from the known and the unknown. J Cell Physiol 182:311-322

39. Lukinius A, Stridsberg M, Wilander E (2003) Cellular expression and specific intragranular localization of chromogranin A, chromogranin $\mathrm{B}$, and synaptophysin during ontogeny of pancreatic islet cells: an ultrastructural study. Pancreas 27:38-46

40. Jonsson J, Carlsson L, Edlund T, Edlund H (1994) Insulinpromoter-factor 1 is required for pancreas development in mice. Nature 371:606-609

41. Gerrish K, Gannon M, Shih D et al (2000) Pancreatic beta cellspecific transcription of the pdx-1 gene. The role of conserved upstream control regions and their hepatic nuclear factor 3 beta sites. J Biol Chem 275:3485-3492

42. Heimberg H, Bouwens L, Heremans Y, Van De CM, Lefebvre V, Pipeleers D (2000) Adult human pancreatic duct and islet cells exhibit similarities in expression and differences in phosphorylation and complex formation of the homeodomain protein Ipf-1. Diabetes 49:571-579

43. Bouwens L, Pipeleers DG (1998) Extra-insular beta cells associated with ductules are frequent in adult human pancreas. Diabetologia 41:629-633

44. Tanaka S, Kobayashi T, Nakanishi K et al (2001) Evidence of primary beta-cell destruction by $\mathrm{T}$ cells and beta-cell differentiation from pancreatic ductal cells in diabetes associated with active autoimmune chronic pancreatitis. Diabetes Care 24:1661-1667

45. Phillips JM, O'Reilly L, Bland C, Foulis AK, Cooke A (2007) Patients with chronic pancreatitis have islet progenitor cells in their ducts, but reversal of overt diabetes in NOD mice by antiCD3 shows no evidence for islet regeneration. Diabetes 56:634640 